\title{
Static Compression Test And Analysis of Honeycomb Paperboard
}

\author{
Baozhong Wang \\ Hebei United University, No.46, Xinhua West Road, \\ Tang Shan City, Hebei Province, China \\ Wangbzhong666@sohu.com
}

\begin{abstract}
Through the static compression test, the thesis has researched on the performance of static compression on honeycomb paperboard with different thickness and different nest. The research has also explained the process of the static compression on honeycomb paperboard with double diamond nest. The test shows that the double diamond nest can improve the cushioning performance of honeycomb paperboard. Double diamond honeycomb paperboard and double hexagonal honeycomb paperboard are selected to test the compression for comparative analysis. The result is that the static compressibility of double diamond honeycomb paperboard is better.
\end{abstract}

Keywords- honeycomb paperboard. static compression. cushioning performance

\section{INTRODUCTION}

As a kind of environmental protection type of honeycomb paperboard cushioning packaging material, with light weight, high strength, high stiffness, good buffering performance, good structural stability and many other advantages. Moreover, the material of the honeycomb paperboard can be fully recycled, no pollution, meet the " $4 \mathrm{R}+\mathrm{lD}$ " green packaging requirements. It can be used for the production of packaging boxes, trays, liners, a gusset, retaining edge, used for electronic products, household appliances, large and medium-sized equipment transport packaging ${ }^{[1]}$.

Honeycomb paperboard is a viscoelastic material, when subjected to external loads, tissue can be impinged upon by gluing surface is passed to the honeycomb paper core, core paper deformation and impact energy absorption after less than can be stored or in the form of heat loss, so that the external force to the mechanical products can reduce, play protection effect. Influence of the cushioning performance of honeycomb paperboard were major factors on the mechanical properties of honeycomb paperboard, paper moisture content and paper honeycomb core structure and mechanical properties of. The ${ }^{[2-4]}$ mainly on the different thickness of honeycomb paperboard cushioning properties were investigated and analyzed. This paper studies the material parameters, temperature and relative humidity on the static cushioning properties of honeycomb paperboard effect, analyzes the similarities and differences of buffer properties. The research can be applied to improve the cushioning performance of honeycomb paperboard honeycomb paperboard products, as well as the structural design and optimization ${ }^{[5-6]}$.

\author{
Shan Gao \\ Hebei United University, No.46, Xinhua West Road, \\ Tang Shan City, Hebei Province, China \\ 582934067@qq.com
}

\section{EXPERIMENTAL MATERIALS AND METHODS}

1) the test material sampling: all samples are placed from $24 \mathrm{~h}$ over the finished drawn. Sample in accordance with national standards, selection of sample surface smooth, glossy paper and paper honeycomb core solid paste, while at the same time to choose sizing with moderate amount of sample, not too much or too little. If the resin content is too much, the honeycomb cardboard surface would be too hard, test data distortion; sizing quantity nor too little, too few will make the paper and core paper paste is not firm, or simply not paste, the surface paper is tilted. These two cases are tests that should be paid attention to and must be avoided, in order to ensure the accuracy of test data. The test materials all come from Tanghai Yuan Ming honeycomb cardboard factory, paper weight of $300 \mathrm{~g} / \mathrm{m} 2$, weight $120 \mathrm{~g} / \mathrm{m} 2$ core paper, coating weight is $110 \mathrm{~g} / \mathrm{m} 2$, honeycomb paper core paper thickness is $0.4 \mathrm{~mm}$, thickness $0.18 \mathrm{~mm}$. Single layer $20 \mathrm{~mm}, 40 \mathrm{~mm}$ rhombic honeycomb and hexagonal honeycomb two, double $20 \mathrm{~mm}$, $40 \mathrm{~mm}$ rhombic honeycomb and hexagonal honeycomb two, size regular rectangular shape, length and width are $200 \mathrm{~mm} \times 200 \mathrm{~mm}$.

2) test: test method using A method to test, test speed is $12 \pm$ $3 \mathrm{~mm} / \mathrm{min}$, along the thickness direction of the test sample to increase load. If the test sample is filamentous, granular materials, due to its specialty of materials can be used to test compression box. During the compression process if the computer running at the same time records of the compression force and its corresponding deformation curve. If the computer apparatus abnormality cannot simultaneously recorded continuous compressive force deformation curve, should measure fifteen points or more ( more precise ) compression force and the corresponding deformation value, and put them into a continuous curve.

When the compressive load increased dramatically when the stop test to load 3min later on test samples, thickness measurement, as testing samples after the test thickness.

\section{THE TEST PRINCIPLE AND EQUIPMENT}

The test adopts the method of compression load at low applied in packaging materials, to get the load displacement curve for package cushioning materials.

Equipment test is used in ZXYD-5023 type FCL compressor Changchun City small testing machine factory. The test instrument control part and an operation part, 
control part is the measurement and control system of a computer and testing software as the core, the computer is equipped with a Windows-XP system, the user in operation is simple and intuitive, contains the pressure testing, force tracking, measuring and testing methods of displacement, brought the great convenience to the test, due to the decline in the upper pressing plate can only test equipment to a certain height, when the honeycomb cardboard is not up to the stroke limit should be placed on the supporting platform of certain height, so the design of the platform.

Through the analysis of the use of steel materials to design table and column, in the form of threaded connection and table is fixed. The maximum force measurement test for $50 \mathrm{KN}$, by calculating the reasonable design support platform.

\section{CALCULATION METHOD}

1) the compression stress:

$$
\sigma=\frac{P}{A} \times 10^{4}
$$

Type of:

$$
\sigma \text { - compressive stress, } \mathrm{Pa} \text {; }
$$

$\mathrm{P}$ - compression load, N;

A - test sample loading area, $\mathrm{cm}^{2}$.

The calculated stress of specimen of apparent stress, on the honeycomb paperboard, is a honeycomb core cross section stress, because of the deformation of the process of tissue stress effect is very small, can be neglected.

2) the compression strain:

$$
\varepsilon=\frac{x}{t} \times 100 \%
$$

Type of:

$$
\begin{aligned}
& \mathcal{E} \text { - compressive strain, \%; } \\
& t \text { - Sample sample of the original thickness, cm; } \\
& x \text { - Test samples in the experiment process of } \\
& \text { thickness deformation, cm. }
\end{aligned}
$$

\section{EXPERIMENTAL RESULTS AND ANALYSIS}

In the honeycomb paperboard compression test, the ZXYD-5023 type FCL compression test machine speed adjustment for $12 \pm 3 \mathrm{~mm} / \mathrm{min}$, along the thickness direction of the applied load, in the compression process computer system automatically generates and records the load displacement curve. This list is only a double thickness of $40 \mathrm{~mm}$ honeycomb paperboard compression curve in figure 1and figure2. According to the load - displacement curve and data using MATLAB software for polynomial fitting drawing stress - strain curves of figure 3 .

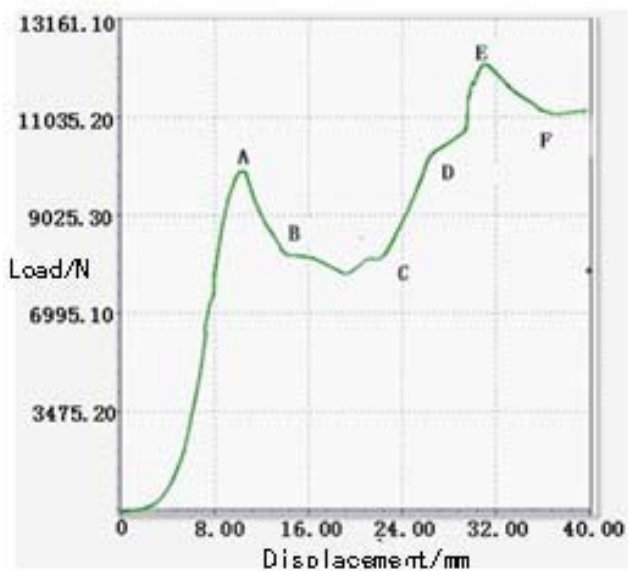

Fig.1 Load-displacement curve of $40 \mathrm{~mm}$ thick double layer rhombic honeycomb paperboard

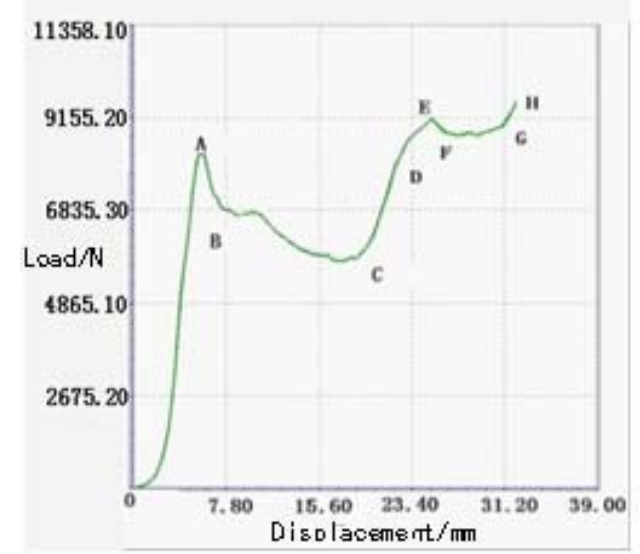

Fig.2 Load-displacement curve of $40 \mathrm{~mm}$ thick double layer hexagon honeycomb paperboard

From the test results of Fig 1 and Fig 2load displacement curve can have, double $40 \mathrm{~mm}$ thick rhombic honeycomb paperboard and the maximum carrying capacity for the $12100 \mathrm{~N}$, double $40 \mathrm{~mm}$ thick hexagon honeycomb paperboard and the maximum carrying capacity for the $9155 \mathrm{~N}$, more available double $40 \mathrm{~mm}$ thick rhombic honeycomb paperboard capacity more stronger. 


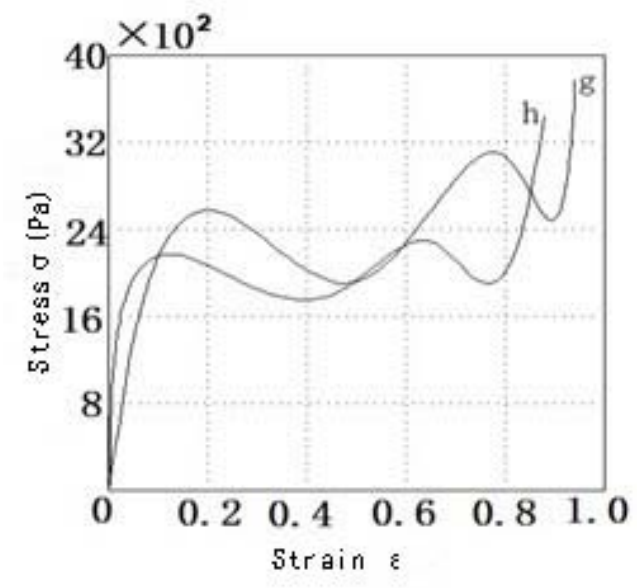

Rhombic-g hexagon-h

Fig. 3 stress-strain curve of $40 \mathrm{~mm}$ thick honeycomb paperboards

\section{CONCLUSIONS}

Based on the static compression test the load-displacement curve data analysis, and the corresponding stress strain curve of the following important conclusions can be drawn:
1) in the same thickness of honeycomb paperboard, plies of the same, nest core rhombic honeycomb paperboard capacity in the nest core for hexagon bearing capacity; 2) in the same thickness of honeycomb paperboard core at the same time, nest, bilayer honeycomb paperboard capacity and cushioning performance of honeycomb paperboard is higher than that of single bearing capacity.

[1] Zhikun Zhang. The relative humidity on the static compression properties of honeycomb paperboard test study of the influence of [J]. packaging engineering, 2008.29 ( 9): 12-13.

[2] Yanfeng Guo, Jinghui Zhang, Wencai Xu. The honeycomb paperboard and the research on the cushion properties of [J]. packaging engineering. 2002.23 ( 5): 110-112.

[3] Danhua He. honeycomb corrugated composite cardboard on the mechanical properties of 2008 6-7. [D]. Guangxi: Guangxi University.

[4] Hailun Wang, Xing Zhang, etc. The core of honeycomb cardboard slotted flat compression strength effect of [J]. packaging Journal 2010.2 (4): 61-63.

[5] Yong Xie, Dejian Zhao. The core of slotting technology on the cushioning performance of honeycomb paperboard effect [J]. Journal of Hunan University of Technology. 2011.25 ( 5): 21-23.

[6] Wang D M, Wang Z W. Out-of-plane compressive proper-ties of hexagonal paper Honeycombs[J]. Chinese journal of mechanical engineering, 2007, 20 (2) : 115-119. 